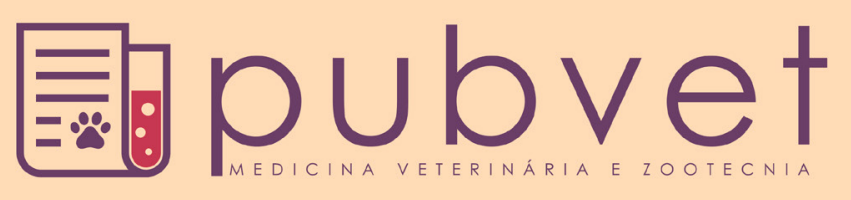

HTTP://DX.DOI.ORG/10.22256/PUBVET.VI1N6.575-580

\title{
Actinobacilose bovina: Revisão
}

\section{Yanne Aciole da Silva ${ }^{1}$, Wendel de Souza Mendonça ${ }^{1}$, Alcir Martins Pereira ${ }^{1}$, Francisco das Chagas Cardoso Junior ${ }^{1}$, Francisco Solano Feitosa Junior ${ }^{2}$, Taciana Galda da Silva Tenório $^{2 *}$}

${ }^{1}$ Médico(a)s Veterinário(a) Autônomo(a).

${ }^{2}$ Professor(a) do Departamento de clinica e Cirurgia Veterinária da Universidade Federal do Piauí, UFPI, Teresina, PI.

*Autores para correspondência: e-mail: tacianagalba@yahoo.com.br

RESUMO. A actinobacilose é uma enfermidade caracterizada por produzir inflamação piogranulomatosa crônica nos tecidos moles e cadeia linfática da cabeça e pescoço. Ocorre mundialmente de forma esporádica, com maior frequência em bovinos, embora também possa acometer ovinos, suínos, equinos e caprinos. O agente etiológico é Actinobacillus lignieresii, um cocobacilo Gram negativos da família Pasteurellacea que, habita as superfícies das mucosas oral e gástrica. A infecção ocorre por meio de soluções de continuidade na cavidade oral ou na pele provocado por alimentos duros ou grosseiros, podendo acometer diversos órgãos de forma sistêmica ou isolada. $\mathrm{O}$ tratamento baseia nas aplicações de iodetos em várias doses no caso de iodeto de potássio, ou em dose única quando utiliza iodeto de sódio, além de terapia com antibióticos de largo espectro. Esse trabalho teve como objetivo uma atualização sobre o tema actinobacilose bovina desde sua etiologia, epidemiologia, patogenia, manifestações clínicas, diagnósticos, tratamento, prognóstico, controle e prevenção.

Palavras-chave: língua de madeira, bovino, clínica veterinária.

\section{Bovine Actinobacillosis: Review}

ABSTRACT. Actinobacillosis AND A disorder characterized IN produce inflammation piogranulomatosa chronic nsa soft tissues and lymphatic chain of the Head and Neck. Occurs worldwide sporadically, more frequently in cattle, although ALSO MAY affect sheep, pigs, horses and goats. The etiologic agent and Actinobacillus lignieresii a Gram negative coccus family Pasteurellacea que, dwelleth as surface of the oral and gastric mucosa. The infection occurs FOR continuity solutions Half the oral cavity, OR in the skin caused BY OR hard coarse foods, can affect Several systemically Bodies OR Isolated. Treatment based NAS Halide Applications in various doses If no iodide Potassium, OR at doses Single When using sodium iodide, in addition to therapy with broad spectrum antibiotics. This study aimed An Update About bovine Actinobacillosis theme from YOUR etiology, epidemiology, pathogenesis, Clinical Manifestations, Diagnosis, treatment, prognosis, Disease Control and Prevention.

Key words: wooden tongue, bovine, veterinary clinic.

\section{Actinobacilosis bovina: Revisión}

RESUMEN. La actinobacilosis es una enfermedad caracterizada por producir inflamación piogranulomatosa crónica en los tejidos blandos y la cadena linfática de la cabeza y el cuello. Se presenta en todo el mundo de forma esporádica, con mayor frecuencia en bovinos, sin embrago, también puede afectar ovinos, porcinos, equinos y caprinos. El agente etiológico es Actinobacillus lignieresii, un cocobacilo Gram negativos de la familia 
Pasteurellacea que, habita la superficie de las mucosas oral y gástrica. La infección ocurre por medio de soluciones de continuidad en la cavidad bucal o en la piel provocada por alimentos duros o gruesos, pudiendo obtener varios tipos de forma sistémica o aislada. El tratamiento se basa en aplicaciones de yoduro a dosis múltiples (en el caso de yodo de potasio), o en dosis única cuando usa de yodo de sodio, además de la terapia con antibióticos de amplio espectro. Este trabajo tuvo como objetivo abordar el tema de la actinobacilosis bovina desde su etiología, epidemiología, patogenia, manifestaciones clínicas, diagnósticos, tratamiento, pronóstico, control y prevención.

Palabras clave: Lengua de madera, bovino, clínica veterinaria.

\section{Introdução}

A actinobacilose é uma enfermidade infecciosa, porém não contagiosa, geralmente crônica, causada por Actinobacillus sp. e, apresenta-se como inflamação piogranulomatosa dos tecidos e cadeia linfática da cabeça e pescoço(Radostits et al., 2010, Gelberg, 2012). Ocorre de todo o mundo de forma esporádica, acometendo habitualmente bovinos e com menos frequência ovinos, equinos, suínos e caprinos (Coetzer et al., 1994, Riet-Correa et al., 2007, Radostits et al., 2010). O agente responsável por causar a doença em ruminantes é Acinobacillus lignieressi, cocobacilus Gram negativa que existe normalmente na cavidade bucal e o rumem destes animais (Rebhun et al., 1988, Radostits et al., 2010, Riet-Correa et al., 2007). Nos suínos a actinobacilose é provocada pelo Acinobacillus suis; enquanto nos equinos o patógeno é Actinobacillus equili (Ohara, 2006, Fraser et al., 1996). Benaoudia et al. (1994) relataram a infecção por Actinobacillus lignieresii em humano decorrente de mordedura por cavalo, ressaltando possível implicação zoonótica. $\mathrm{O}$ primeiro relato de actinobacilose em bovinos foi descrito em 1902 por Ligniéresis e Spitz na Argentina, quando analisaram em pequenos grânulos de pus de abscessos subcutâneos múltiplos na cabeça e pescoço de bovinos, a presença de cocos Gram negativos (Aquino, 2010).

Esse trabalho teve como objetivo uma atualização sobre o tema actinobacilose bovina, uma das principais infecções responsáveis pela condenação de carcaças e abatedouros, além de ocasionar perdas econômicas relevantes para a pecuária, abordando desde sua etiologia, epidemiologia, patogenia, manifestações clínicas, diagnósticos, tratamento, prognóstico, controle e prevenção.

\section{Etiologia}

A actinobacilose tem como agente etiológico o Actinobacillus lignieresii, um cocobalilo Gram- negativo e imóvel da família Pasteurellaceae, aeróbico e anaeróbico facultativo, em cultivo cresce bem em ágar sangue, e possui ainda, baixa resistência às condições do meio ambiente, pois, não sobrevive por mais de cinco dias em feno ou palhas (Pugh, 2005, Riet-Correa et al., 2007, Radostits et al., 2010). O A. Lignieresii normalmente habita as superfícies mucosas do trato digestório dos bovinos, ovinos e possivelmente dos caprinos (Rebhun et al., 1988, Aquino, 2010).

A alimentação com forragem abrasiva ou espinhosa e erupções ou abrasões dentárias constituem os principais fatores de risco para actinobacilose, por ocasionarem lesões na mucosa oral e, portanto, propiciar acesso a corrente sanguínea e/ou linfática, por conseguinte instalação nos linfonodos adjacentes e em outros tecidos (Riet-Correa et al., 2007).

Existem trabalhos relacionando à infecção de A. lignieresii com lacerações, injeção intravenosa, linfadenite disseminada e cirurgias de implante de argola nasal e descorna cosmética (Rebhun et al., 1988, Radostits et al., 2010, Carvalho et al., 2015). Riet-Correa et al. (2007) citam a via aerógena como forma de aquisição de actinobacilose e responsável por desenvolver a forma pulmonar da desta doença.

Para Campbell et al. (1975), os animais com lesões supurativas são fonte de propagação do microrganismo para o ambiente, contaminando alimentos, cochos e bebedouros (Coetzer et al., 1994, Riet-Correa et al., 2007, Peli et al., 2009, Radostits et al., 2010).

\section{Epidemiologia}

De distribuição mundial, a actinobacilose acomete bovinos, ovinos, equídeos, suínos e caprinos, sem distinção de idade e sexo, porém, ocorre mais frequente em bovinos, de forma esporádica e associada à ingestão de forragens de baixa qualidade (Riet-Correa et al., 2007, Radostits et al., 2010, Rebhun and Oliveira, 2000). 
Radostits et al. (2010) ressaltam que áreas com deficientes de cobre esta associada a aumento da incidência de actinobacilose.

Os principais locais de afecção nos bovinos são a língua parcial ou totalmente e os linfonodos da cabeça e do pescoço, principalmente nos linfonodos retrofarígeos, parotídeos e submandibulares. De forma atípica ou generalizada pode acometer outro tecidos como pré-estômagos, fígado, pulmões, coração, rins, útero e pele (Franco, 1970, Coetzer et al., 1994, Riet-Correa et al., 2007). Enquanto em ovinos, devido forma de apreensão dos alimentos diferente dos bovinos, as lesões prevalecem nos lábios e bochechas que eventualmente pode atingir às mucosas dos ossos turbinados e aos tecidos moles da cabeça e pescoço (Radostits et al., 2010).

Surto de actinobacilose está associado grande concentração de animais em uma determinada área aliado a alta morbidade do A. lignieresii que pode ser até a 73\% (Radostits et al., 2010). Lesões extraordinárias ocasionadas, pela passagem de sondas nasais, punções por agulhas múltiplas ou feridas decorrentes de brigas também favorecem a disseminação da doença, pelo contato com as secreções salivares (Correa et al., 1992; Helio, 1997; Smith, 2006).

No Brasil a morbidade varia entre 1-90\% (Riet-Correa et al., 2007). Mondadori et al. (1994) relatam surto de actinobacilose no Rio Grande do Sul em bovinos jovens mantidos em pastagem de resíduos de arroz ou soja. E Brasil (2012) descreve em seu trabalho mais de 12 mil condenações de carcaças em abatedouros submetidos ao Serviço de Inspeção Federal no ano de 2012. Enquanto, Baptista (1999) expõe a prevalência de $0,0126 \%$ de lesões características de actinobacilose em abatedouros em Minas Gerais com inspeção federal.

\section{Patogenia}

A infecção ocorre quando o Actinobacillus lignieresi, microrganismo comensal da cavidade oral e trato digestivo, invade os tecidos por meio de erosões ou lacerações na mucosa e na pele, produzindo reações infamatórias agudas que, por conseguinte evolui para lesões granulomatosa, gerando necrose e supuração de tecidos moles (Rebhun and Oliveira, 2000, Riet-Correa et al., 2007, Radostits et al., 2010). Quando a bactéria atingir os vasos linfáticos acomete os linfonodos regionais, provocando linfadenite piogranulomatosa (Rebhun and Oliveira, 2000,
Radostits et al., 2010). Essas lesões são constantemente encontradas em linfonodos retrofaríngeos durante a fiscalização de abatedouros (Quinn et al., 2005).

Em bovinos, a infecção sucede-se, frequentemente, por meio de lesões penetrantes ou ulceradas do sulco da língua ou nas lesões penetrantes na extremidade da língua e ferimentos na superfície lateral do corpo da língua causado pelos dentes, apresentando sob a forma de glossite difusa podendo acometer toda a língua ou segmentos da mesma, posteriormente, essa inflamação é substituída por tecido fibroso, consequentemente, a musculatura da língua tornase contraída e imóvel, prejudicando a apreensão e deglutição de alimentos (Radostits et al., 2010).

De forma variável, podem ocorrer úlceras na porção dorsal da língua que desprende um pus amarelo e inodoro, ou nódulos amarelados disseminados na mucosa e nas partes laterais (Rebhun and Oliveira, 2000, Riet-Correa et al., 2007, Radostits et al., 2010). Contudo, pode ocasionar mastite crônica ou aguda, pneumonia supurativa, artrite séptica, endocardite vegetativa, endometrite, sinusite crônica, infeções umbilicais, vesiculite seminal e infeção secundária em ferimentos, tanto em bovinos como em ovinos e suínos (Quinn et al., 2005, Rebhun and Oliveira, 2000, Gyles et al., 2008). Outros autores descrevem ainda, apresentações incomuns em bovinos nas glândulas salivares, na pele, no tecido subcutâneo da cabeça e pescoço, no esôfago, estômagos e omento (Till and Palmer, 1960, Campbell et al., 1975, Sheikh-Omar, 1980, Rebhun et al., 1988, Radostits et al., 2010).

\section{Sinais clínicos}

Devido a sua sintomatologia clássica, a actinobacilose geralmente é conhecida como "língua de pau" ou "língua de madeira", uma vez que, a língua é o órgão mais comumente afetado (Rebhun et al., 1988, Riet-Correa et al., 2007, Radostits et al., 2010).

À palpação encontra-se rigidez e aumento de volume na base da língua, além de sensível e dolorosa a manipulação, sialorréia e eventual protrusão da língua. $\mathrm{O}$ animal demostra mastigação suave da língua, como se um corpo estranho estivesse presente na boca (Radostits et al., 2010), dificuldade de se alimentar por um período de aproximadamente 48 horas (Aquino, 2010) e nota-se aumento de volume da área submandibular. Os nódulos observados na 
superfície da língua variam de tamanho, podendo ser alguns milímetros a aproximadamente três centímetros de diâmetros, com pequenos grânulos amarelados, semelhantes a grãos de enxofre (Bazargani et al., 2010).

Os linfonodos submaxilares e parótideos apresentam palpáveis e visivelmente aumentados de volume e, pode desenvolver tumefação firme que eclodem e liberam pus ralo e inodoro (Radostits et al., 2010). A condição corporal do animal pode esta prejudicada decorrente da interferência do aumento da cadeia linfática à deglutição, resultando desidratação, apatia e óbito, caso não for realizado uma intervenção terapêutica (Ohara, 2006, Radostits et al., 2010).

Podem ocorrem lesões atípicas nos lábios, palato, faringe, fossas nasais, face e pálpebras, com presença de granulomas da actinobacilose com vários centímetros de diâmetro, moles à palpação, vermelhos e sangram com facilidade (Radostits et al., 2010). Os bovinos quando acometidos por lesões difusas na face caracterizam um quadro clínico denominado de “cara de hipopótamo" (Aquino, 2010).

\section{Diagnóstico clínico}

O diagnóstico clínico baseia-se nos achados clínicos descritos anteriormente e histórico do animal, bem como, no exame histopatológico da lesão.

$\mathrm{Na}$ avaliação do material purulento, tratado com hidróxido de sódio a 5\% e lavado em água destilada, constata- se a presença de estruturas semelhantes a grânulos de enxofre, patognomônicos de Actinobacillus lignieresii (Riet-Correa et al., 2007, Radostits et al., 2010). Ao realizar o esfregaço do pus, verificam-se estruturas semelhantes a clavas distribuídas radialmente, com massa de bactérias no centro e presença de infiltrados de linfócitos e plasmócitos, neutrófilos, macrófagos e/ou células gigantes multinucleadas, bem como, tecido de granulação e fibrose reativa (Tessele et al., 2013). Enquanto, no esfregaço com coloração de Gram, faz-se a pesquisa de cocobacilos gram-negativos no pus contendo grânulos (Pugh, 2005, Riet-Correa et al., 2007).

Os grânulos encontrados na actinobacilose por Actinobacillus lignieresii também são verificados em exsudato purulento dos granulomas ocasionados por Actinomyces bovis, Pseudomonas aeruginosa e Staphylococcus aureus. No entanto, a confirmação, é tida com o isolamento e identificação de Actinobacillus lignieresii (Rebhun et al., 1988, Riet-Correa et al., 2007).

\section{Diagnóstico diferencial}

O diagnóstico diferencial esta relacionado a corpos estranhos na língua; raiva, em virtude da salivação abundante; e a tuberculose, pois, lesões pulmonares causas pelo $A$. lignieresii se assemelham as lesões verificadas nessa patologia, sendo dessa forma, a actinobacilose responsável pela maioria das condenações de carcaças em abatedouros (Aquino, 2010, Radostits et al., 2010, Tessele et al., 2013).

\section{Tratamento}

Adota-se iodeto de sódio ou iodeto de potássio como tratamento padrão para actinobacilose, no entanto, indícios laboratoriais deduzem que os iodetos são ineficaz como bactericida sobre o Actinobacillus lignieresii, sugerindo que esses fármacos possuem mecanismo de ação sobre redução da gravidade da reação do tecido fibroso (Radostits et al., 2010).

A administração do iodeto de potássio é recomendada por via oral na dose de 6 a $10 \mathrm{~g} / \mathrm{dia}$ durante sete a 10 dias, na qual pode ser adicionado na água de bebida do animal. Esse tratamento pode ser prolongado até o aparecimento da sintomatologia de iodismo, como lacrimejamento, anorexia, tosse e aparecimento de caspa. O iodeto de sódio a $10 \%$ é aplicado na dose de $1 \mathrm{~g} / 12 \mathrm{~kg}$ de peso corpóreo por via IV, em dose única (Pugh, 2005, Riet-Correa et al., 2007, Radostits et al., 2010). Ambos os protocolos são eficientes para uma resposta entre 24 à $48 \mathrm{~h}$ após o tratamento, desfazendo as lesões do tecido mole e os sinais de actinobacilose (Radostits et al., 2010).

Rebhun et al. (1988) descrevem uma terapia com iodeto de sódio a $20 \%$ intravenoso na dose de $30 \mathrm{mg} / 450 \mathrm{~kg}$ de peso corpóreo, em intervalos de dois a três dias, até que o aparecimento de iodismo, e o fornecimento oral de $30 \mathrm{~g}$ de iodo orgânico para cada $450 \mathrm{Kg}$, duas vezes ao dia após a terapia intravenosa inicial, até atingir nível máximo de iodo sistêmico. Ocasionalmente os efeitos colaterais após o tratamento com iodetos incluem desconforto, como inquietação, dispnéia, taquicardia, incoordenação e aborto em vacas com gestação adiantada (Radostits et al., 2010).

Ainda é relevante a associação de protocolo com iodetos e administração de antibióticos de largo espectro. Pesquisas revelam sensibilidade do Actinobacillus lignieresii a ceftiofur, ampicilina, 
penicilina, florfenicol, sulfas, aminoglicosídeos e tetraciclina (Riet-Correa et al., 2007, Radostits et al., 2010).

\section{Controle e prevenção}

Fornecimento de forragem de qualidade, evitando alimentos espinhosos ou grosseiros, que favorecem a lacerações na cavidade oral, tratamento e isolamento ou remoção de animais com lesões supurativas constituem as principais medidas de controle de actinobacilose, além de manter em quarentena animais providos de regiões ou propriedade com histórico da doença (RietCorrea et al., 2007, Radostits et al., 2010).

\section{Referências Bibliográficas}

Aquino, M. H. B. 2010. Prevalência da Actinobacilose em ruminantes no Hospital Veterinário da Universidade Federal de Campina Grande - 2005/2010. Centro de Saúde e Tecnologia Rural. Universidade Federal de Campina Grande., Campina Grande.

Bazargani, T. T., Tafti, A. K., Atyabi, N. \& Faghanizadeh, G. H. 2010. An unusual occurrence of actinobacillosis in heifers and cows in a dairy herd in Tehran suburb-Iran. Archives of Razi Institute, 65, 105-110.

Benaoudia, F., Escande, F. \& Simonet, M. 1994. Infection due toActinobacillus lignieresii after a horse bite. European Journal of Clinical Microbiology \& Infectious Diseases, 13,439440.

Campbell, S. G., Timoney, J. F. \& Underwood, A. M. 1975. An unusual epizootic of actinobacillosis in dairy heifers. Journal of the American Veterinary Medical Association, 166, 604-606.

Carvalho, A. M., Toma, H. S., Artmann, T. A., Spohr, K. A. H., Nascimento Pinheiro, J. C. M. \& Camargo, L. M. 2015. Actinobacilose em bovino secundária a descorna cosmética: relato de caso. Veterinária e Zootecnia, 22, 32-36.

Coetzer, J. A. W., Thomson, G. R. \& Tustin, R. C. 1994. Infectious diseases of livestock with special reference to Southern Africa. University Press, Cape Town.

Franco, D. A. 1970. Generalized actinobacillosis in a Holstein cow (postmortem lesions). Veterinary medicine, small animal clinician, $65,562$.
Fraser, C. M., Bergeron, J. A., Mays, A. \& Aiello, S. A. 1996. Manual Merck de Veterinária: um manual de diagnóstico, tratamento, prevenção e controle de doenças para o veterinário. Roca.

Gelberg, H. B. 2012. Alimentary System and peritoneum, omentum, mes $\neg$ entery, and peritoneal cavity. In: Zachary, J. F., McGavin, D. \& McGavin, M. D. (eds.) Pathologic Basis of Veterinary Disease. Elsevier, St. Louis.

Gyles, C. L., Prescott, J. F., Songer, J. G. \& Thoen, C. O. 2008. Pathogenesis of bacterial infections in animals. John Wiley \& Sons, Iowa, University.

Ohara, P. M. 2006. Microbiologia e histopatologia de linfonodos de bovinos com lesões macroscópicas sugestivas de tuberculose. Colheitas efetuadas de Maio/2002 à Janeiro/2004, São Paulo, Brasil. Faculdade de Medicina e Vetrinária. Universidade de São Paulo, São Paulo.

Peli, A., Spadari, A., Romagnoli, N., Bettini, B., Scarpa, F. \& Pietra, M. 2009. An atypical case of respiratory actinobacillosis in a cow. Journal of Veterinary Science, 10, 265-267.

Pugh, D. G. 2005. Clínica de ovinos e caprinos. Editora Roca, São Paulo.

Quinn, P. J., Markey, B. K., Carter, M. E., Donnelly, W. J. \& Leonard, F. C. 2005. Microbiologia veterinária e doenças infecciosas. Artmed, Porto Alegre.

Radostits, O. M., Gay, C. C., Blood, D. C., Hinchcliff, K. W. \& McKenzie, R. A. 2010. Clínica Veterinária: um tratado de doenças dos bovinos, ovinos, suínos, caprinos e eqüinos. Guanabara Koogan, Rio de Janeiro.

Rebhun, W. C., King, J. M. \& Hillman, R. B. 1988. Atypical actinobacillosis granulomas in cattle. The Cornell veterinarian, 78, 125-130.

Rebhun, W. C. \& Oliveira, P. M. A. 2000. Doenças do gado leiteiro. Roca, São Paulo.

Riet-Correa, F., Méndez, F., Carmen Schild, M., Riet-Correa, A. L. F., Schild, A. L. \& Carmen, M. M. 2007. Doenças de ruminantes e eqüinos. Varela, Sãp Paulo.

Sheikh-Omar, A. R. 1980. Actinobacillosis of the omentum in a cow. Pertanika, 3, 64-65.

Tessele, B., Brum, J. S. \& Barros, C. S. L. 2013. Lesões parasitárias encontradas em bovinos 
abatidos para consumo humano. Pesquisa Veterinária Brasileira, 33, 873-889.

Till, D. H. \& Palmer, F. P. 1960. A review of actinobacillosis with a study of the causal organism. Veterinary Record, 72, 527-533.
Article History:

Received 20 February 2017

Accepted 27 March 2017

Available on line 19 May 2017

License information: This is an open-access article distributed under the terms of the Creative Commons Attribution License 4.0, which permits unrestricted use, distribution, and reproduction in any medium, provided the original work is properly cited. 